\title{
Sistem Pendukung Keputusan Penentuan Jurusan dengan Metode Simple Additive Weighting (SAW) untuk Meningkatkan Keakuratan Dalam Menentukan Jurusan Siswa Di Ma Tanwiriyyah
}

\author{
Sri Widaningsih ${ }^{1}$, Yuli Yuliani ${ }^{2}$ \\ Program Studi Teknik Informatika \\ Fakultas Teknik Universitas Suryakancana \\ widaningsihsri@gmail.com ${ }^{1}$,yuliyuliani398@gmail.com²
}

\begin{abstract}
Abstrak
Proses penentuan jurusan di MA Tanwiriyyah dilakukan dengan cara tes pada masing-masing siswa, kemudian nilai-nilai tersebut dihitung dan hasilnya dijadikan dasar untuk menentukan jurusan apa yang sesuai untuk siswa. Dalam hal penentuan jurusan terjadi beberapa permasalahan yaitu banyaknya siswa sehingga dibutuhkan waktu yang lama, dalam proses perhitungan yang dilakukan masih menggunakan teknik perhitungan manual dan juga membutuhkan hal penunjang lainnya seperti biaya pengeluaran yang lebih besar untuk membeli kertas dan percetakan soal-soal tes. Hal itu menyebabkan masalah diantaranya terjadi kesalahan dalam keakuratan hasil perhitungan, kesulitan menentukan jurusan yang sesuai dengan bakat dan kemampuan siswa.

Sistem Pendukung Keputusan penentuan jurusan metode SAW karena metode tersebut merupakan metode yang digunakan untuk mencari alternatif optimal dari sejumlah alternatif dengan penjumlahan terbobot dari rating kinerja pada setiap alternatif, metode ini dinilai cocok untuk permasalahan yang dihadapi karena melibatkan penilaian dari tiap kriteria dan dihasilkan output berupa ranking prioritas.

Sistem Pendukung Keputusan menggunakan metode Simple Additive Weighting (SAW) berbasis dekstop dibuat sedemikian rupa agar dapat memenuhi kebutuhan pengguna dan menghasilkan sistem yang membantu pelaksanaan kinerja di instansi, sehingga memudahkan dalam pendataan siswa, memudahkan dalam melakukan tes jurusan, mempermudah dalam penentuan jurusan yang sesuai dengan bakat dan kemampuan siswa di MA Tanwiriyyah.
\end{abstract}

Kata Kunci : Sistem pendukung keputusan, Metode Simple Additive Weighting (SAW), Desktop

\section{Pendahuluan}

\subsection{Latar Belakang Masalah}

Pendidikan adalah usaha sadar dan terencana untuk mewujudkan suasana belajar dan proses pembelajaran agar prestasi didik secara aktif mengembangkan potensi dirinya untuk memiliki kekuatan spiritual keagamaan, pengendalian diri, kepribadian, kecerdasan, akhlak mulia, serta keterampilan yang diperlukan dirinya, masyarakat, bangsa dan Negara (UU No. 20 Tahun 2003 tentang Sisdiknas). Penentuan jurusan merupakan salah satu bagian penting dalam proses pendidikan. Keputusan yang diambil dalam penentuan jurusan diharapkan sesuai dengan nilai akademik dan kemampuan siswa. Sehingga dibutuhkan sistem pendukung keputusan yang dapat memproses data-data penjurusan dan menghasilkan keputusan yang tepat. Sistem pendukung keputusan merupakan sebuah sistem informasi yang menggunakan model keputusan, sebuah database dan sebuah wawasan dari pembuat keputusan dalam sebuah proses pemodelan yang ad hoc dan interaktif untuk mencapai sebuah keputusan yang spesifik oleh seorang pembuat keputusan yang spesifik (James O'Brien dan George M, 2014:285). Metode Simple Additive Weighting (SAW) merupakan salah satu metode yang digunakan untuk menyelesaikan masalah dari Multiple Attribute Decision Making (MADM), Simple Additive Weighting (SAW) yaitu suatu metode yang digunakan untuk mencari alternatif optimal dari sejumlah alternatif dengan kriteria tertentu. Metode Simple Additive Weighting (SAW) sering juga dikenal istilah metode penjumlahan terbobot. Konsep dasar metode SAW adalah mencari penjumlahan terbobot dari rating kinerja pada setiap alternatif pada semua atribut (Pahlevy. 2010).

MA Tanwiriyyah merupakan salah satu sekolah yang berlokasi di Jln. Aria Wiratanudatar Km. 05 Sindanglaka - Karangtengah Cianjur. Di sekolah ini terdiri dari tiga jurusan yaitu jurusan Matematika Ilmu Alam (MIA), Ilmu Ilmu Sosial (IIS), dan Ilmu Ilmu Keagamaan (IIK). Proses pendaftaran calon siswa di MA Tanwiriyyah ini dilakukan secara manual yaitu diawali pada saat siswa melakukan pendaftaran dengan mengisi formulir pendaftaran dan mencantumkan minat untuk jurusan 1 dan jurusan 2. Setelah itu melakukan tes pada masing-masing siswa, tes tersebut terdiri dari tes matematika, ilmu pengetahuan alam, ilmu pengetahuan sosial, bahasa indonesia, dan ilmu agama. Kemudian nilai-nilai tersebut dihitung dan hasilnya dijadikan dasar untuk menentukan jurusan apa yang sesuai untuk siswa. Dalam hal penentuan jurusan terjadi beberapa permasalahan yaitu banyaknya siswa sehingga waktu yang dibutuhkan dalam menentukan jurusan yang sesuai dengan kemampuan siswa semakin lama. Proses perhitungan yang dilakukan masih menggunakan teknik 
Sri Widaningsih ${ }^{1}$, Yuli Yuliani ${ }^{2}$, Sistem Pendukung Keputusan Penentuan Jurusan dengan Metode Simple Additive Weighting (SAW) untuk Meningkatkan Keakuratan Dalam Menentukan Jurusan Siswa Di Ma Tanwiriyyah

perhitungan manual sehingga sering terjadi kesalahan dalam keakuratan hasil perhitungan karena belum tersedianya program (aplikasi) khusus untuk mendukung perhitungan tersebut. Kesulitan siswa dalam menentukan jurusan yang sesuai dengan minat dan kemampuan siswa masing-masing. Pelaksanaan penentuan jurusan secara manual membutuhkan hal penunjang lainnya seperti biaya pengeluaran yang lebih besar untuk membeli kertas dan percetakan soal-soal tes. Pentingnya penentuan jurusan ini dimaksudkan agar nanti siswa dapat menyelesaikan sekolah sesuai dengan minat dan kemampuannya sebelum melanjutkan ke jenjang yang lebih tinggi. Hal ini tentunya diperlukan ketepatan dalam penentuan jurusan dikarenakan akan sangat berdampak pada masa depan siswa nantinya apabila siswa salah memilih jurusan, maka dikhawatirkan akan muncul permasalahan baik pada saat sekolah ataupun nanti pada saat jenjang yang lebih tinggi. Oleh karena itu diperlukannya sebuah sistem pendukung keputusan untuk menentukan jurusan pada siswa MA Tanwiriyyah. Sistem Pendukung Keputusan adalah salah satu cara mengorganisir informasi yang digunakan dalam membuat keputusan. Pembuatan sistem pendukung keputusan ini diharapkan akan menyelesaikan permasalahan yang dihadapi dan sistem yang dibangun nantinya menggunakan kriteria-kriteria yang relevan sehingga hasil akhir dapat menjadi acuan terhadap jurusan yang akan dipilih sesuai dengan bakat dan kemampuan siswa di MA Tanwiriyyah.

Dari permasalahan di atas maka dibutuhkan suatu sistem pendukung keputusan dimana sistem tersebut mampu membantu pihak sekolah dalam melaksanakan kegiatan penentuan jurusan, mampu mempermudah siswa mengetahui jurusan yang tepat sesuai dengan kemampuannya, serta mampu menyajikan informasi mengenai kemampuan siswa yang nantinya bisa dijadikan sebagai acuan dalam menentukan jurusan yang sesuai dengan kemampuan berdasarkan nilai akademiknya, semua sistem tersebut harus secara sistematis, terpadu dan terkordinasi secara cermat, cepat dan tepat sasaran. Berdasarkan permasalahan di atas maka judul penelitian ini adalah "Sistem Pendukung Keputusan Penentuan Jurusan dengan Metode Simple Additive Weighting (SAW) untuk Meningkatkan Keakuratan dalam Menentukan Jurusan Siswa di MA Tanwiriyyah”.

\subsection{Rumusan Masalah}

Berdasarkan latar belakang masalah tersebut maka rumusan masalah dari penelitian ini adalah bagaimana membangun sebuah Sistem Pendukung Keputusan Penentuan Jurusan dengan Metode Simple Additive Weighting (SAW) untuk Meningkatkan Keakuratan dalam Menentukan Jurusan Siswa di MA Tanwiriyyah.

\subsection{Maksud dan Tujuan}

Maksud dari penelitian ini adalah membangun sebuah sistem secara terkomputerisasi yang mampu membantu pihak sekolah dalam melaksanakan kegiatan penentuan jurusan, mampu mempermudah siswa mengetahui jurusan yang tepat sesuai dengan kemampuannya, serta mampu menyajikan informasi mengenai kemampuan siswa yang nantinya bisa dijadikan sebagai acuan dalam menentukan jurusan yang sesuai dengan kemampuan berdasarkan nilai akademiknya.

Adapun tujuan yang didapat dari penelitian ini adalah :

a. Memudahkan dalam proses pendataan siswa.

b. Memudahkan proses perhitungan nilai tes penentuan jurusan.

c. Memudahkan dalam pengambilan keputusan untuk menyeleksi siswa berdasarkan nilai akademik.

d. Membantu pembuat keputusan di MA Tanwiriyyah dalam menentukan hasil penjurusan siswa.

e. Mampu menyajikan informasi mengenai kemampuan siswa yang nantinya bisa dijadikan sebagai acuan dalam menentukan jurusan yang sesuai dengan kemampuan serta prestasi akademiknya.

\subsection{Batasan Masalah}

Agar ruang lingkup permasalahan yang diambil tidak terlalu luas, maka diperlukan batasan masalah untuk memperjelas dan memfokuskan pembahasan sistem yang akan dibangun. Berikut ini merupakan batasan masalah yang dibahas, diantaranya:

a. Pembuatan sebuah fungsi yang memudahkan dalam pendataan siswa.

b. Pembuatan sebuah fungsi yang menyediakan soalsoal tes penentuan jurusan.

c. Pembuatan sebuah fungsi yang memudahkan perhitungan nilai tes penentuan jurusan.

d. Sistem Pendukung Keputusan (SPK) ini menyajikan informasi mengenai kemampuan siswa yang nantinya bisa dijadikan sebagai acuan dalam menentukan jurusan yang sesuai dengan kemampuan serta prestasi akademiknya.

e. Metode yang digunakan dalam Sistem Pendukung Keputusan (SPK) adalah SAW (Simple Additive Weighting) dengan batasan sebagai berikut :

- Variabel input yang digunakan dibatasi lima variabel, yaitu variabel nilai matematika, variabel nilai ilmu pengetahuan alam, variabel nilai ilmu pengetahuan sosial, variabel nilai bahasa indonesia, dan variabel nilai ilmu agama.

- Variabel output yang digunakan adalah jurusan Matematika Ilmu Alam (MIA), Ilmu Ilmu Sosial (IIS), dan Ilmu Ilmu Keagamaan (IIK).

\section{Landasan teori}

\subsection{Pengertian Sistem Pendukung Keputusan}

Sistem Pendukung Keputusan adalah pendekatan berbasis komputer atau metodologi untuk mendukung pengambilan keputusan. Bagian paling penting dari SPK khas adalah data warehouse, yang merupakan subjek berorientasi, terpadu, waktu-varian, non-normalisasi, koleksi non-volatile data yang memungkinkan menganalisis sejumlah besar data dari berbagai sumber dengan hasil yang cepat (Turban, 2005).

\subsection{Simple Additive Weighting (SAW)}


Metode Simple Additive Weighting (SAW) sering juga dikenal istilah metode penjumlahan terbobot. Konsep dasar metode SAW adalah mencari penjumlahan terbobot dari rating kinerja pada setiap alternatif pada semua atribut (Fishburn,1967) (MacCrimmon, 1968).

\section{a. Normalisasi Matriks}

Metode SAW membutuhkan proses normalisasi matriks keputusan (X) ke suatu skala yang dapat diperbandingkan dengan semua rating alternatif yang ada.

$$
r_{i j}= \begin{cases}\frac{X_{i j}}{\operatorname{Max}_{i} X_{i j}} & \text { Jika j adalah atribut keuntungan (benefit) } \\ \frac{\operatorname{Min}_{i} X_{i j}}{X_{i j}} & \text { Jika j adalah atribut biaya (cost) }\end{cases}
$$

Dimana :

Rij = Rating kinerja ternormalisasi

maxi = Nilai maksimum dari setiap baris dan kolom.

Mini = Nilai minimum dari setiap baris dan kolom.

Xij $\quad=$ Baris dan kolom di matriks.

(rij) adalah rating kinerja ternormalisasi dari alternatif pada atribut $I=1,2, \ldots, m$ dan $j=1,2, \ldots, n$.

\section{b. Nilai Preferensi}

Nilai preferensi untuk setiap alternatif Vi diberikan sebagai :

$$
V_{i}=\sum_{j=1}^{n} w_{j} r_{i j}
$$

Keterangan :

$\mathrm{V}_{\mathrm{i}} \quad=$ rangking untuk setiap alternatif

$\mathrm{w}_{\mathrm{j}} \quad=$ nilai bobot dari setiap kriteria

$\mathrm{r}_{\mathrm{ij}} \quad=$ nilai rating kinerja ternormalisasi

Nilai $V_{i}$ yang lebih besar mengindikasikan bahwa alternatif $\mathrm{A}_{\mathrm{i}}$ lebih terpilih.

\subsection{Pemecahan Masalah dengan Menggunakan Metode Simple Additive Weighting (SAW)}

\subsubsection{Kriteria dan Bobot}

Dalam metode Simple Additive Weighting (SAW) terdapat kriteria yang dibutuhkan untuk menentukan jurusan yang sesuai dengan kemampuan siswa. Adapun kriteria sebagai berikut :

Tabel 1 Kriteria

\begin{tabular}{|l|l|}
\hline Kode Kriteria & Kriteria \\
\hline $\mathrm{C} 1$ & Matematika \\
\hline $\mathrm{C} 2$ & IPA \\
\hline $\mathrm{C} 3$ & IPS \\
\hline $\mathrm{C} 4$ & Bahasa Indonesia \\
\hline $\mathrm{C} 5$ & Ilmu Agama \\
\hline
\end{tabular}

Dari masing-masing kriteria tersebut akan ditentukan bobotnya. Untuk lebih jelas, data bobot sebagai berikut :

Tabel 2 Bobot Untuk Kriteria

\begin{tabular}{|c|c|c|c|}
\hline Kriteria & $\begin{array}{l}\text { Bobot } \\
\text { kriteria }\end{array}$ & $\begin{array}{l}\text { Kode } \\
\text { kriteria }\end{array}$ & $\begin{array}{l}\text { Bobot } \\
\text { Referensi }\end{array}$ \\
\hline Matematika & $20 \%$ & $\mathrm{C} 1$ & 0,2 \\
\hline IPA & $20 \%$ & $\mathrm{C} 2$ & 0,2 \\
\hline IPS & $20 \%$ & $\mathrm{C} 3$ & 0,2 \\
\hline $\begin{array}{c}\text { Bahasa } \\
\text { Indonesia }\end{array}$ & $20 \%$ & $\mathrm{C} 4$ & 0,2 \\
\hline Ilmu Agama & $20 \%$ & $\mathrm{C} 5$ & 0,2 \\
\hline
\end{tabular}

\subsubsection{Tabel Alternatif}

\begin{tabular}{|l|l|}
\multicolumn{2}{c}{ Tabel 3 Alternatif } \\
\hline Kode Alternatif & Keterangan \\
\hline MIA & Matematika Ilmu Alam \\
\hline IIS & Ilmu Ilmu Sosial \\
\hline IIK & Ilmu Ilmu Keagamaan \\
\hline
\end{tabular}

\subsubsection{Menentukan Tabel Rating Kriteria \\ Kecocokan}

Dalam menentukan rating kriteria kecocokan ada dua kriterian yang berbeda disesuaikan dengan alternatif

Tabel 4 Rating Kecocokan

\begin{tabular}{|l|l|l|}
\hline Alternatif & $\begin{array}{c}\text { Kriteria Yang } \\
\text { Diunggulkan }\end{array}$ & \multicolumn{1}{|c|}{$\begin{array}{c}\text { Kriteria Nilai } \\
\text { Biasa }\end{array}$} \\
\hline MIA & Matematika, IPA & $\begin{array}{l}\text { IPS, Bahasa } \\
\text { Indonesia , Ilmu } \\
\text { Agama }\end{array}$ \\
\hline IIS & Matematika, IPS & $\begin{array}{l}\text { IPA, Bahasa } \\
\text { Indonesia , Ilmu } \\
\text { Agama }\end{array}$ \\
\hline IIK & $\begin{array}{l}\text { Matematika , Ilmu } \\
\text { Agama }\end{array}$ & $\begin{array}{l}\text { IPA, IPS , Bahasa } \\
\text { Indonesia }\end{array}$ \\
\hline
\end{tabular}

Tabel 5 Kriteria Nilai Yang Diunggulkan

\begin{tabular}{|c|c|c|}
\hline Nilai & Klasifikasi & Rating \\
\hline $91-100$ & Sangat Baik & 5 \\
\hline $81-90$ & Baik & 4 \\
\hline $71-80$ & Cukup & 3 \\
\hline $51-70$ & Kurang & 2 \\
\hline $0-50$ & Sangat Kurang & 1 \\
\hline
\end{tabular}

Tabel 6 Kriteria Nilai Biasa

\begin{tabular}{|c|c|c|}
\hline Nilai & Klasifikasi & Rating \\
\hline $81-100$ & Sangat Baik & 5 \\
\hline $61-80$ & Baik & 4 \\
\hline $41-60$ & Cukup & 3 \\
\hline $21-40$ & Kurang & 2 \\
\hline $0-20$ & Sangat Kurang & 1 \\
\hline
\end{tabular}




\subsubsection{Perhitungan Seleksi Penentuan Jurusan}

Sebagai contoh seorang calon siswa bernama Ana melakukan pendaftaran di MA Tanwiriyyah. Nilai yang dimiliki oleh Ana setelah melakukan tes adalah sebagai berikut: Nilai Tes Matematika $=80$, Nilai Tes IPA $=85$, Nilai Tes IPS $=60$, Nilai Tes Bahasa Indonesia $=70$, Nilai Tes Ilmu Agama $=80$.

- $\quad$ Rating kecocokan pada setiap alternatif

\begin{tabular}{|c|c|c|c|c|c|}
\hline Alternatif & C1 & C2 & C3 & C4 & C5 \\
\hline MIA & 3 & 4 & 3 & 4 & 4 \\
\hline IIS & 3 & 5 & 2 & 4 & 4 \\
\hline IIK & 3 & 5 & 3 & 4 & 3 \\
\hline
\end{tabular}

- Tahapan Normalisasi

Alternatif ke 1

$$
\begin{aligned}
& \text { R } 11=3 / 3=1.00 \\
& \text { R } 12=4 / 5=0.80 \\
& \text { R } 13=3 / 3=1.00 \\
& \text { R } 14=4 / 4=1.00 \\
& \text { R } 15=4 / 4=1.00
\end{aligned}
$$

Alternatif ke 2

$$
\begin{gathered}
\text { R } 21=3 / 3=1.00 \\
\text { R } 22=5 / 5=1.00 \\
\text { R } 23=2 / 3=0.66 \\
\text { R } 24=4 / 4=1.00 \\
\text { R } 25=4 / 4=1.00
\end{gathered}
$$

Alternatif ke 3

$$
\begin{aligned}
& \text { R 31 }=3 / 3=1.00 \\
& \text { R 32 }=5 / 5=1.00 \\
& \text { R 33 }=3 / 3=1.00 \\
& \text { R 34 }=4 / 4=1.00 \\
& \text { R 35 }=3 / 4=0.75
\end{aligned}
$$

- Hasil Normalisasi

$\mathrm{R}\left[\begin{array}{lllll}1.00 & 0.80 & 1.00 & 1.00 & 1.00 \\ 1.00 & 1.00 & 0.66 & 1.00 & 1.00 \\ 1.00 & 1.00 & 1.00 & 1.00 & 0.75 \\ & & & & \end{array}\right]$

- Mencari nilai alternatif yaitu penjumlahan dari perkalian matriks ternormalisasi $\mathrm{R}$ dengan vektor bobot sehingga diperoleh nilai alternatif Perbaikan bobot adalah :

$$
\begin{aligned}
& \mathrm{W}=\left[\begin{array}{lllll}
0,2 & 0,2 & 0,2 & 0,2 & 0,2
\end{array}\right] \\
& \mathrm{W}_{\text {MIA }}=(1.00 * 0,2)+(0.80 * 0,2)+(1.00 * 0,2)+ \\
& (1,00 * 0,2)+(1.00 * 0,2)=\mathbf{0 , 9 6} \\
& \mathrm{W}_{\text {IIS }}=(1.00 * 0,2)+(1.00 * 0,2)+(0,66 * 0,2)+ \\
& (1,00 * 0,2)+(1.00 * 0,2)=\mathbf{0 , 9 3} \\
& \mathrm{W}_{\mathrm{IIK}}=(1.00 * 0,2)+(1.00 * 0,2)+(1.00 * 0,2)+ \\
& (1,00 * 0,2)+(0.75 * 0,2)=\mathbf{0 , 9 5}
\end{aligned}
$$

Berdasarkan perhitungan tersebut dengan demikian alternatif MIA (Matematika Ilmu Alam) adalah alternatif yang dapat dipilih sebagai rekomendasi jurusan terhadap calon siswa tersebut (Ana).

\section{Analisis Dan Perancangan Sistem}

\subsection{Analisis Pengguna}

Analisis Pengguna mendefinisikan siapa saja yang menggunakan sistem dan apa saja yang didapat dilakukan oleh pengguna di dalam sistem. Berikut merupakan pengguna dari sistem pendukung keputusan mengenai penentuan jurusan:

- $\quad$ Staff Tata Usaha

Staff Tata Usaha (petugas) bertugas melakukan pengontrolan dan pengelolaan data atau penggunaan sistem secara penuh.

- $\quad$ Siswa

Siswa memiliki fungsi untuk melakukan tes jurusan.

\subsection{Analisis Kebutuhan Fungsional}

Aplikasi yang dibangun harus mempunyai fungsi utama yang mendukung pemecahan masalah yang ada pada sebuah organisasi. Fungsi yang dimaksud berbentuk layanan-layanan yang diberikan oleh aplikasi. Beberapa fungsi utama dalam Sistem Pendukung Keputusan Penentuan Jurusan dengan Metode Simple Additive Weighting (SAW) untuk Meningkatkan Keakuratan dalam Menentukan Jurusan Siswa di MA Tanwiriyyah adalah sebagai berikut :

- Memiliki fasilitas login.

- Memiliki fasilitas pendataan siswa.

- Memiliki fasilitas soal untuk melakukan tes seleksi jurusan.

- Melakukan pengecekan jawaban tes seleksi jurusan.

- Melakukan proses perhitungan menggunakan metode Simple Additive Weighting (SAW).

- Memiliki fasilitas kelola jurusan.

- Memiliki fasilitas pembuatan laporan.

\subsection{Use Case Diagram}

Use Case Diagram mendeskripsikan kelakuan sistem dari sudut pandang pengguna, berguna untuk membantu memahami kebutuhan. Use case adalah dasar dari diagram lain. Use case adalah abstraksi dari interaksi antara sistem dan actor. Use case bekerja dengan mendeskripsikan tipe interaksi antara actor sebuah sistem dengan sistemnya sendiri melalui sebuah cerita bagaimana sebuah sistem dipakai. Berikut merupakan use case diagram dari sistem pendukung keputusan penentuan jurusan : 


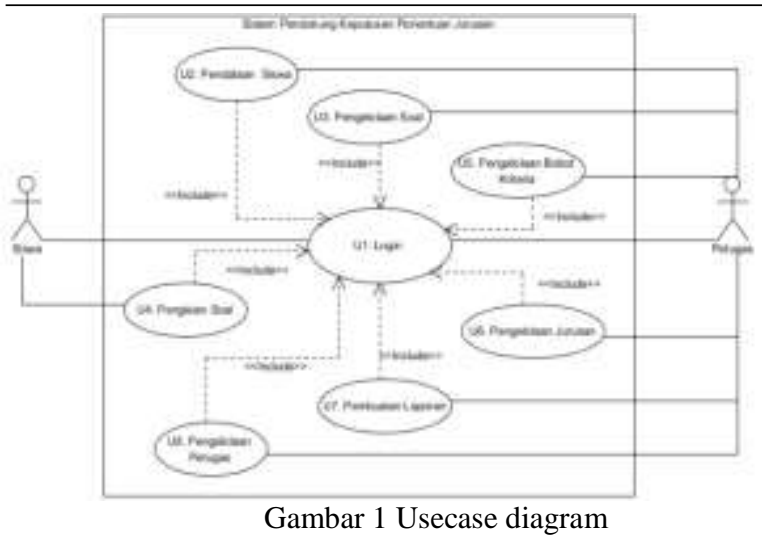

Berdasarkan Gambar 1 Use Case Diagram Sistem Pendukung Keputusan Penentuan Jurusan, terdapat 2 aktor dan 8 use case yaitu Petugas dan Siswa. Petugas dan siswa harus terlebih dahulu melakukan Login kemudian mendapatkan hak akses terhadap Sistem Pendukung Keputusan Penentuan Jurusan. Mulai dari mengelola pendataan siswa, mengelola soal, mengelola bobot kriteria, mengelola jurusan, pembuatan laporan dan mengelola petugas.

\subsection{Class diagram}

Class diagram adalah pandangan aplikasi yang statis. Class diagram tidak hanya menggambarkan visualisasi, menggambarkan dan mendokumentasikan aspek yang berbeda dalam sistem, tetapi juga untuk kontruksi eksekusi kode dalam software aplikasi .

Class diagram digunakan untuk mengelompokkan hal-hal inti dari setiap proses yang ingin dilakukan. Semua proses dimasukkan ke dalam tiap-tiap Class dan saling dihubungkan pada Class-Class lainnya yang saling berhubungan.

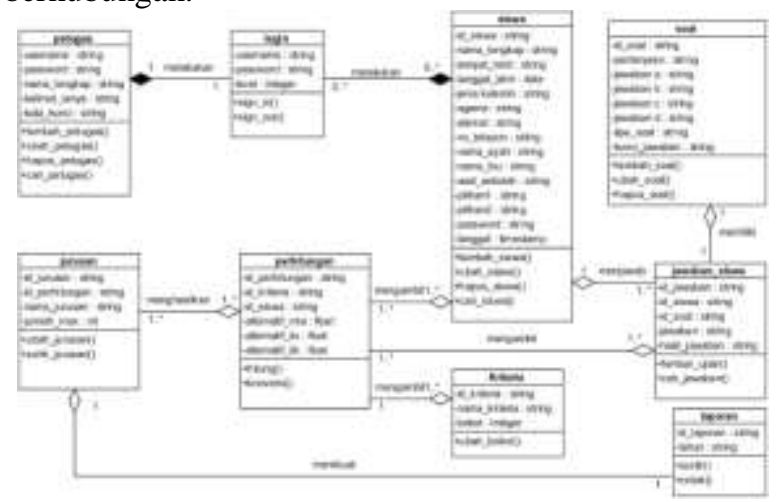

Gambar 2 Class Diagram dari Sistem Pendukung Keputusan Penentuan Jurusan

\section{Antarmuka Sistem}

\subsection{Antarmuka Login}

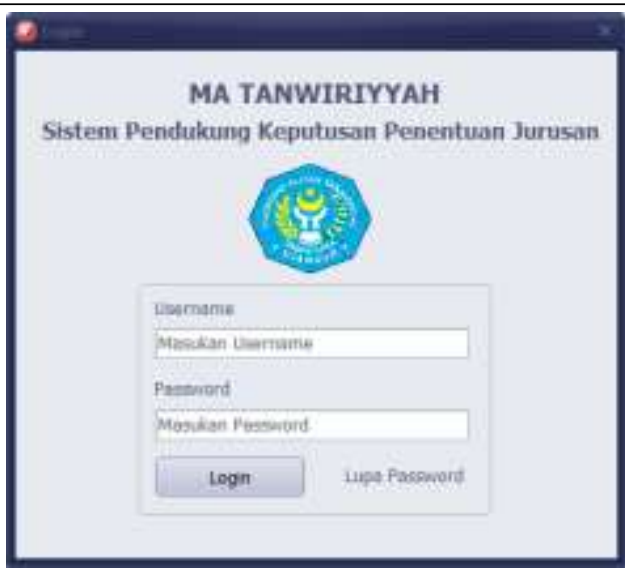

Gambar 3 Login

\subsection{Antarmuka Halaman Utama Petugas}

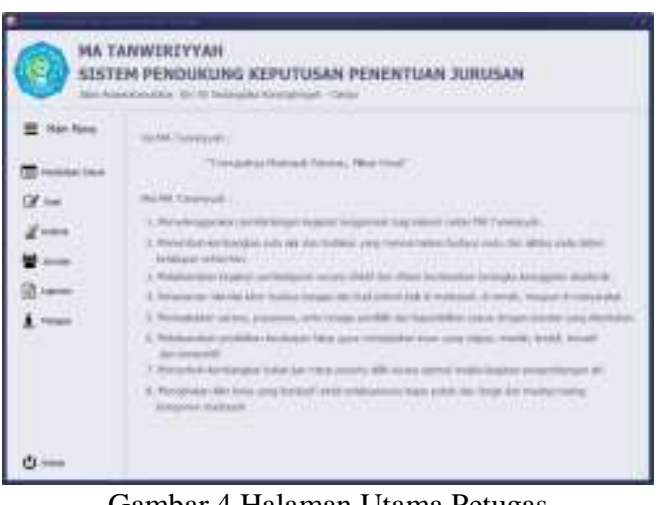

Gambar 4 Halaman Utama Petugas

\subsection{Antarmuka Halaman Utama Siswa}

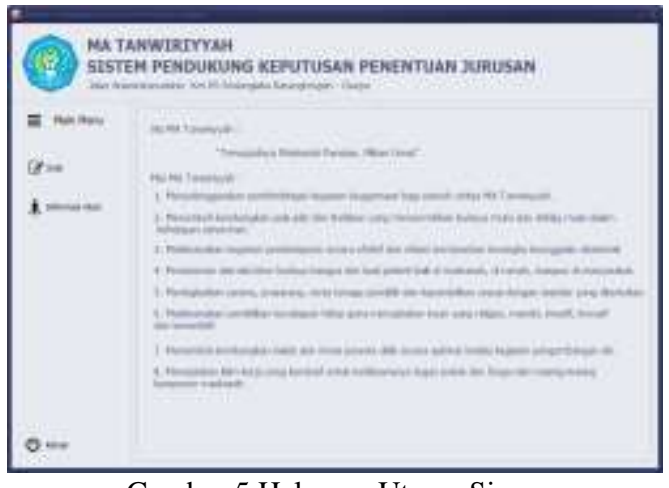

Gambar 5 Halaman Utama Siswa

\subsection{Halaman Soal Siswa}

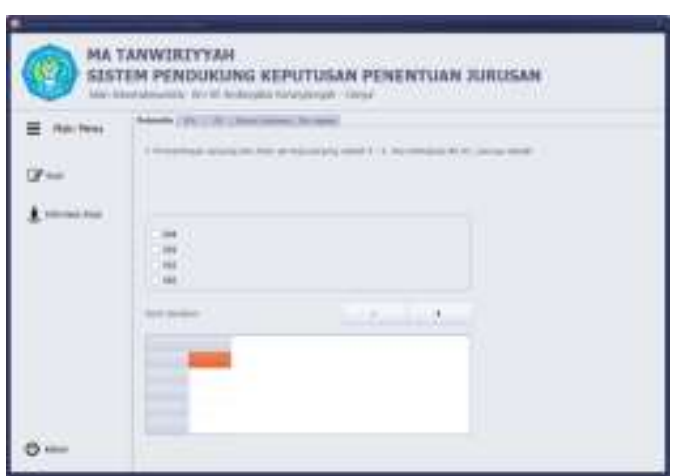


Sri Widaningsih ${ }^{1}$, Yuli Yuliani ${ }^{2}$, Sistem Pendukung Keputusan Penentuan Jurusan dengan Metode Simple Additive Weighting (SAW) untuk Meningkatkan Keakuratan Dalam Menentukan Jurusan Siswa Di Ma Tanwiriyyah

Gambar 6 Halaman Soal Siswa

\subsection{Antar Muka Pendataan Siswa}

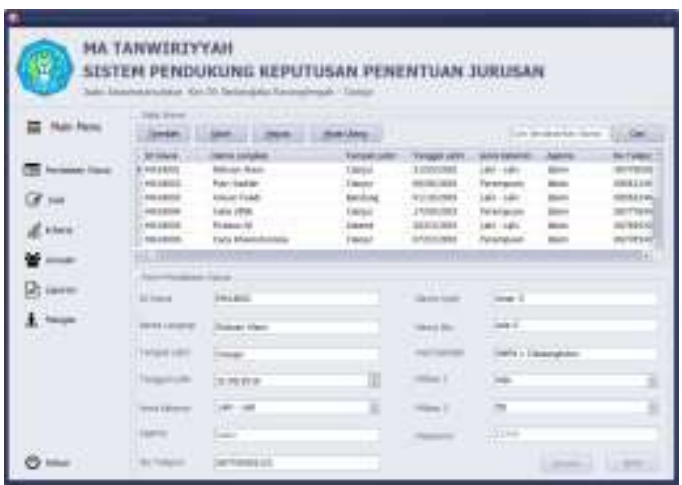

Gambar 7 Halaman Pendataan Siswa

\subsection{Antar Muka Halaman Soal}

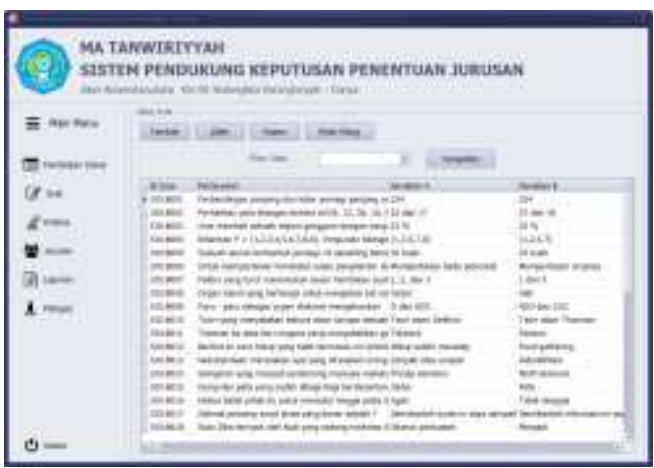

Gambar 8 Halaman Soal

\subsection{Antar Muka Halaman Kriteria}

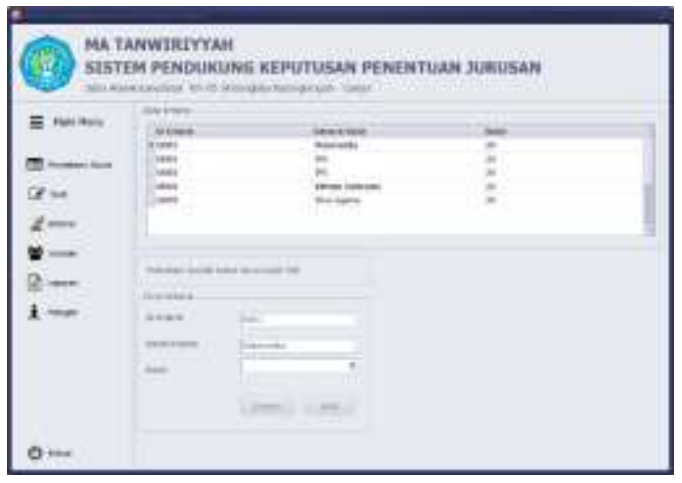

Gambar 9 Halaman Kriteria

\subsection{Antar Muka Halaman Jurusan}

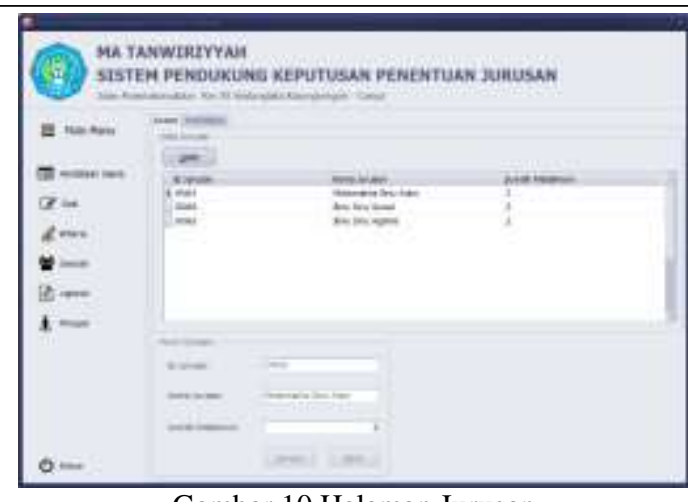

Gambar 10 Halaman Jurusan

\subsection{Antar Muka Halaman Hasil Seleksi}

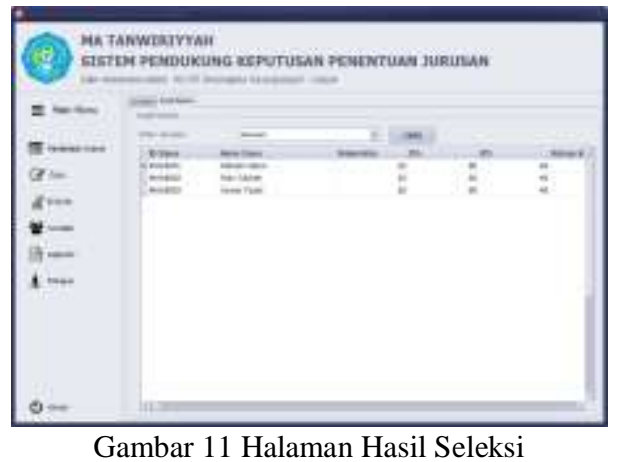

\subsection{Antar Muka Halaman Laporan}

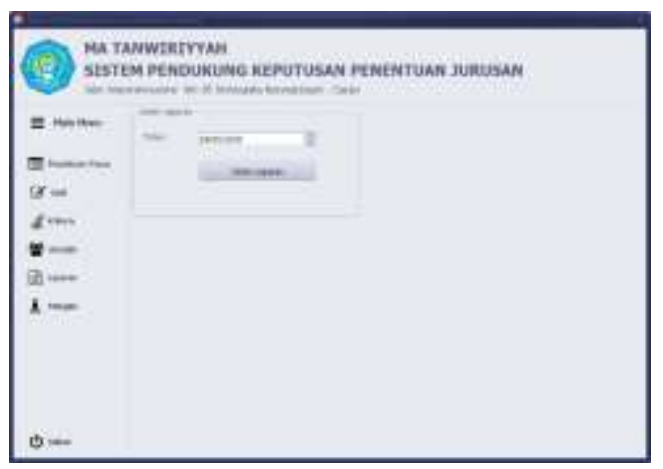

Gambar 12 Halaman Laporan

\subsection{Antar Muka Halaman Petugas}

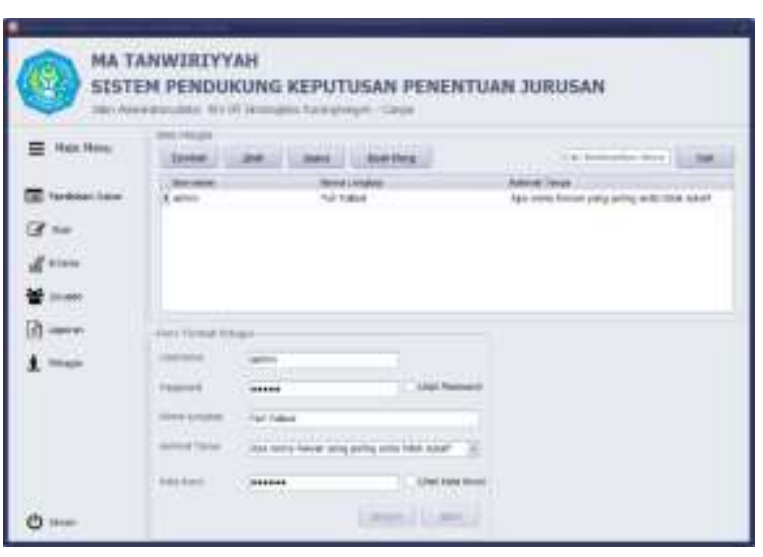

Gambar 13 Halaman Petugas

\section{Simpulan}


Berdasarkan hasil analisis selama melaksanakan penelitian Di MA Tanwiriyyah yang berjudul Sistem Pendukung Keputusan Penentuan Jurusan dengan Metode Simple Additive Weighting (SAW) untuk Meningkatkan Keakuratan dalam Menentukan Jurusan Siswa di MA Tanwiriyyah, dapat disimpulkan bahwa :

- Sistem pendukung keputusan ini adalah solusi di tujukan kepada panitia penentuan jurusan agar mudah untuk menentukan jurusan yang sesuai dengan siswa.

- Sistem ini memudahkan petugas dalam proses pendataan siswa.

- Sistem pendukung keputusan ini memudahkan proses perhitungan nilai tes penentuan jurusan.

- Mampu menyajikan informasi mengenai kemampuan siswa yang nantinya bisa dijadikan sebagai acuan dalam menentukan jurusan yang sesuai dengan kemampuan serta prestasi akademiknya.

\section{Saran}

Untuk meningkatkan kinerja Sistem Pendukung Keputusan Penentuan Jurusan dengan Metode Simple Additive Weighting (SAW) untuk Meningkatkan Keakuratan dalam Menentukan Jurusan Siswa di MA Tanwiriyyah, maka penulis mengajukan beberapa saran antara lain :

- Untuk pengembangan selanjutnya dapat dibuatkan aplikasi berbasis web secara online sehingga siswa dalam melakukan proses seleksi jurusan secara online.

- Perlu ada pemeliharaan sistem yang baik menyangkut pemeliharaan data, pemeliharaan perangkat pengelolaan data, maupun pemeliharaan sistem.

\section{Daftar Pustaka}

[1]. Ardian Agung, Y. D. (2009). Analisis dan Desain Sistem Informasi. Bandung: Politeknik Telkom.

[2]. Istikhomah, S. R. (2015). Sistem Pendukung Keputusan Pemilihan Jurusan Pada Smk Negeri 1 Purwosari Menggunakan Metode Simple Additive Weighting (SAW). Malang: STMIK PPKIA Pradnya Paramita Malang.

[3]. Kusrino. (2007). Strategi Perancangan dan Pengelolaan Basis Data. Yogyakarta: ANDI.

[4]. M, J. O. (2014). Management Information System Eight Edition. New York: McGraw-Hill/Irwin.

[5]. MacCrimmon, K. (1968). Decision Making Among Multiple Atribut Alternatives. a survei and Consolidated Approach.

[6]. Pahlevy, R. T. (2010). Rancang Bangun Sistem Pendukung Keputusan Menentukan penerima Beasiswa dengan Menggunakan metode Simple Additive Weughting (SAW). Surabaya: Universitas Pembangunan Nasional.
[7]. Presman, R. S. (2010). Rekayasa Perangkat Lunak : Pendekatan Praktisi. Yogyakarta: Andi Yogyakarta.

[8]. Teuku Mufizar, D. S. (2015). Sistem Pendukung Keputusan Pemilihan Jurusan Dengan Menggunakan Metode SAW (Simple Additive Weighting) Di SMA 6 Tasikmalaya. Tasikmalaya: STMIK Tasikmalaya .

[9]. Turban, E. J. (2005). Decision Support System and Intelegent System. Yogyakarta: Andi.

[10]. Undang - Undang No. 20 Tahun 2003 tentang Sisdiknas 